\title{
Personal Space of Family Members During the Covid-19 Pandemic: The Influence of Noise Factors (Airborne, Impact, and Anthropogenic)
}

\author{
Gubina S.T.* Kirillova E.P.
}

\author{
Vyatka State University, Kirov, Russia \\ *Corresponding author. Email: svetgubina@gmail.com
}

\begin{abstract}
The article presents a study of the problem of the sovereignty of the psychological personal space of family members whose social activity is reduced and who have to live long-term in a confined space during the COVID-19 pandemic. Family members' post-traumatic stress adaptation to environmental influences in the form of acoustic noise was studied. The noise impact on the psychological state of family members was determined, taking into account the characteristics of their personality and the cohabitation conditions and features. There were three types of noise observed: air (the sound intensity level of the human voice, animal sounds, natural phenomena, music streaming, etc.), impact noise (sounds associated with mechanical actions, different types of knocking, footsteps, etc.), and anthropogenic (sounds of transport, working equipment, devices, etc.) Quantitative and qualitative analysis of the research findings showed that acoustic noise can be a factor contributing to the emergence of emotional stress in the subject, and on the other hand, depression and alexithymia contribute to the subject's focusing attention on the surrounding sound space associated with a specific life situation.
\end{abstract}

Keywords: personal space, family, self-isolation, pandemic, acoustic noise

\section{INTRODUCTION}

The current situation as a result of coronavirus infection spread has contributed to changes in many areas of people's lives. Behaviour patterns related to the emerging objective environmental factors, such as observing strict personal hygiene rules, social distancing, etc., have become of current importance. The task was to overcome difficulties in adapting to forced self-isolation and switching to working and studying from home (remote work and study). The essence of this process was a protective adaptation to stressful social demands that raise physical stress, and, as a result, a possible post-traumatic disorder caused by changes in the usual way of life.

Based on the above, people began to develop various individual strategies for overcoming stress and accepting a new life situation. Researcher G. Selye compared conquering stress with the way the body reacts to poison that is removing the poison or ignoring it [1]. Therefore, behaviour in the new conditions can be characterized as an active or passive position, where the key role is the subject's past life experience (his reaction in similar conditions). However, the COVID-19 pandemic provoked a psychological non-normative crisis, where people are faced with a life problem that has not been expected, and cannot be avoided or solved in a short time in the traditional way. To date, there are findings of psychological research indicating increased suicidal thoughts during the pandemic [2], high anxiety and depression, which arouse the feeling of helplessness, largely due to information from the Internet [3], emotional vulnerability, which leads to the aggravated manifestation of panic behaviour [4].

Self-isolation, interaction with people who stay in the same place (apartments, houses, porches, etc.) for a long time (without any possibility of free movement), contributed to the aggravation of violating the boundaries of personal space. We are talking about the sphere around the human body, intruding of which leads to discomfort. Due to the increased closeness of external borders, family members focused (with no distractions) their attention on each other, as it had become almost impossible to continue external contacts that are direct interaction with other people. There was a paradoxical situation in which people following the public call "stay home" in order to keep safe and healthy faced acute problems related to the manifestation of impunity, abuse of power, lack of ethics and respect for the personal space of family members [5]. It was noted that during the pandemic there was a sharp increase in the number of domestic conflicts and violence [6]. Hence, it is relevant to study post-traumatic stress adaptation and ways to meet the need to build psychological defences against environmental influences, taking into account the conditions of home self-isolation. There are many different kinds of interference, one of which is acoustic noise at home that violates people's 
privacy zone: loud speech, mechanical, media sounds, etc. The article presents the findings of research of the correlation between the attitude to personal space and psychological states, taking into account the attitude to the surrounding acoustic noise in everyday life.

\section{THEORETICAL JUSTIFICATION}

Personal (living) space is understood as a system of significant objects and phenomena formed by the subject (including himself/herself), which are in specific connections and relations with each other and perform certain functions and roles. This space is a reality formed by the subject himself/herself, a psychological environment of the individual that has strong personal boundaries and at that the distance between people during interpersonal communication ought to be observed. Spatial psychology researcher E. Hall developed the concept of "proximity" designating four types of distance for interpersonal interaction taking into account the correlation of closeness or distance: intimate, personal, social and public [7, p. 77].

There is a lot of analogy in human behaviour in distancing with the behaviour of animals that pay attention to keeping safe distances in their environment. For example, zoopsychology researcher Konrad Lorenz noted in the book "Aggression, or So-called Evil" that caring about their ("personal") space is natural for birds when many of their species forming large clusters maintain an individual distance between them. For example, the distance between any two starlings sitting on wires corresponds to their ability to reach each other with their beaks. If this interval is violated, a fight starts immediately and does not stop until the necessary interval is established between the birds again. Such rule is maintained only between individuals, while there is no individual distance within the pack and pack animals are not aggressive [8].

The key quality of personal space is the desire for sovereignty (self-ownership), which increases with age, however, if this process is disrupted, the person experiences a personal crisis. In such situation, the problem of speculating about the meaning of life becomes more sensitive and being unable to be in the familiar conditions of relationships and identifications as accustomed: home, work, friends, etc., which are mainly external to the subject's mental reality. The formation of sovereignty occurs by means of the psychological overcoming of difficulties (through the demonstration of active coping behaviour). Otherwise, the learned helplessness (the victim position) develops in the form of an automatically recurring state that occurs in a situation when it seems that external events do not depend on the person, and he/she can do nothing to prevent or modify them. Researcher S. K. Nartova-Bochaver identified six sectors of the individual's psychological space: his/her body, territory, personal belongings, time regime, social connections, tastes (values), noting that normal sovereignty develops throughout the life of the person [9]. Based on the above, for successful adaptation to the conditions of life, it is necessary to develop a sense of selfesteem and meaningfulness in accordance with a person's inner potential. The individual seeks to personalize the environment: to include some places and objects in the sphere of his/her "self", thereby presenting himself/herself to other people, giving symbolic markers to the fact of his/her ownership of a particular place (object). The "projection" of the individual into the surrounding space provides a sense of confidence, security and being in a familiar environment. For example, at home, it is expressed by placing (or "scattering" as involuntary selfexpression) things, the establishment of their own special rules and norms. Demonstrating the sound of voice (its high /low intensity) is a "conductor of intersubjectivity" [10, P. 20], controlling various points of view and the emotional state of people in the affected area. In other words, the sounds of voice, mechanical noise, loud music in the room (which is also a component of the environment) reproduced by the subject can be regarded as a psychological continuation (extension, expansion) of oneself in space. Objects that contribute to the expansion of personal space boundaries can be subjectified naturemade objects: plants, pets, which contribute to the experience of belonging to something big - nature.

The individual influences people who enter his/her psychological space, but also changes himself/herself under their influence. For example, in the family life organization, there may be problematic relationships in which there is an "inverted" hierarchy in the form of excessive psychological fusion among family members, infantile parents or children performing parental functions. Sometimes there is little contact among family members and a relative lack of structure, order and power. In such families, close people are not able to provide adequate positive feedback to each other acting only as a "crooked mirror" in the form of a vicious circle of inadequate response. In this situation, it is impossible to find the "source of all troubles", since the objectivity of thoughts is replaced by emotionality, according to the algorithm: "if he (she, they) ... then I (we)". Family members use various psychological defences in the form of exculpatory rationalization and intellectualization of actions, in order to gain security by emotionally "clinging" to each other. For example, family members may develop "nonacceptance of stroking" (non-acceptance of support), which is based on learned family prohibitions from childhood, respectively, a number of irrational neurotic conclusions [11]. For example, you can not ask for and accept support, even if it is very necessary, devaluing it with counter comments and excuses, because "nothing happens just like that", etc. Family members may show unproductive forms of motivation, such as avoiding real or imagined failures because of the fear of change. In the emerging periods of adaptation, these family members are locked in the space of their own inner world, in which, on the one hand, the characteristics of the reflected objects of the external environment are manifested, and on the other hand, the personal attitude to them is expressed [12]. Quite often, various personally significant objects and events (toys, books, gifts and memories, etc.) that help to adjust 
to the environment can be a means of adaptation. For example, listening to music by himself/herself with headphones can be a means of voluntary regulation of the emotional state, being a subjectified component of the internal environment [13].

\section{RESEARCH METHODS}

From March to June 2020, we conducted research that involved 120 family members who were self-isolated due to the COVID-19 pandemic, 48 women and 36 men aged 24 to 58 years; 36 teenagers aged 12 to 16 years among them.

The purpose of the research was to study the sovereignty of personal boundaries in family members during a period of reduced social activity during a prolonged stay in a confined space, at home.

The following tasks were set:

- to study the interrelation between the individual's psychological space sovereignty and the family environment;

- to determine the influence of noise factors (airborne, impact, and anthropogenic) on the psychological state of family members, taking into account individual characteristics.

Online questioning was conducted with the research participants, where the following psychodiagnostic techniques were used:

Family Environment Scale (FES) method adapted by S. $\mathrm{Yu}$. Kupriyanov, that surveys a number of indicators, which are presented below. The indicator of "relations among family members": commitment (family friendship and mutual assistance), expressiveness (the ability to act openly in various family situations), conflict (how typical are destructive relationships in the family). The indicator of "personal growth": independence (how much family members encourage each other in self-affirmation, selfsufficiency), orientation to achievement (how much family members encourage each other in setting life goals), intellectual-cultural orientation (orientation of family on self-education, study, creative work), orientation to outdoor activities (the existence of a family vacation tradition), moral aspects (respect for family values). Indicators of "family system management": organization (the presence of order and good organization in the family), control (rules and procedures for controlling each other).

The Toronto Alexithymia Scale (TAS) studies the extent of expression of alexithymic personality traits expressed in specific thinking with a lack of emotional responses. Alexithymia manifests itself through the difficulty in identifying feelings and bodily sensations that arise in excitement, as well as in describing (verbalizing) emotions of other people.
"Scale of depression" (Beck Depression Inventory, BDI) developed by A. Beck and studying manifestations of depression, which is understood as a triad of symptoms: mood swings down, inhibited thinking, and decreased physical activity. The method reveals the depression symptom load: cognitive-affective ones (reduced ability to concentrate and mental activity), somatic (sleep disorders, low appetite, problems with perception of one's own body).

"Sovereignty of Psychological Space - 2010" Methodology (by S. K. Nartova-Bochaver), designed to study six types of sovereignty. Physical body sovereignty (somatic well-being), territory sovereignty (security of the physical space where a person is located). World of things sovereignty (attitude to someone's personal property). Sovereignty of habits (attitude to the order, rules, own behavioural settings). Sovereignty of social ties (the right to have friends and acquaintances, etc.) and sovereignty of values (free expression of taste and worldview).

R. M. Hirschfeld Interpersonal Dependency Inventory adapted by O. P. Makushina, revealing the dependence on partners in family relations, manifested through the search for emotional support in others (focus on emotional support and trust), insecurity (expression of doubt in own ability to solve important problems), aspirations for autonomy (the ability to take responsibility for own actions and feelings), the manifestation of dependence (the desire to receive help from others).

Questionnaire for assessing subjective responses to various types of acoustic noise in family members in a situation of long-term living in a confined space during self-isolation. Participants were asked to evaluate the impact of sound from objects identified as sound-reproducing devices, natural phenomena, or living organisms on a 10-point scale.

As hypotheses, the following assumptions were made:

- the psychological space of the individual is associated with the family environment to a greater extent in the context of organizational and managerial issues;

- during a prolonged stay in a confined space, noise (airborne, impact, and anthropogenic) can be an irritating factor that contributes to the development of various destructive mental states.

\section{DISCUSSION OF FINDINGS}

A questionnaire was conducted using the "Sovereignty of Psychological Space - 2010" and "Family Environment Scale" methods, in order to diagnose the interrelation between peculiarities of manifestation of the personal space sovereignty and relationships in the family environment. The Pearson correlation coefficient was used to study the connection between metric variables. The results can be seen in Table 1 . 
Table 1 Correlation between the Sovereignty of Psychological Space and Family Environment

\begin{tabular}{|c|c|c|c|c|c|c|}
\hline \multirow{2}{*}{$\begin{array}{l}\text { Family } \\
\text { environment }\end{array}$} & \multicolumn{6}{|c|}{ Sovereignty of psychological space } \\
\hline & $\begin{array}{l}\text { Sovereignty of the } \\
\text { physical body }\end{array}$ & $\begin{array}{l}\text { Sovereignty of } \\
\text { the territory }\end{array}$ & $\begin{array}{l}\text { Sovereignty of } \\
\text { the world of } \\
\text { things }\end{array}$ & $\begin{array}{l}\text { Sovereignty of } \\
\text { habits }\end{array}$ & $\begin{array}{l}\text { Sovereignty of } \\
\text { social ties }\end{array}$ & $\begin{array}{l}\text { Sovereignty of } \\
\text { values }\end{array}$ \\
\hline Commitment & -0.162 & 0.289 & -0.023 & 0.002 & 0.004 & -0.439 \\
\hline Expressiveness & 0.011 & 0.042 & 0.158 & 0.124 & 0.130 & 0.107 \\
\hline Conflict & 0.320 & -0.203 & 0.003 & 0.329 & 0.102 & 0.006 \\
\hline Independence & 0.090 & -0.709 & 0.032 & -0.429 & 0.026 & 0.078 \\
\hline $\begin{array}{l}\text { Orientation to } \\
\text { achievement }\end{array}$ & 0.077 & 0.030 & 0.142 & 0.021 & 0.003 & 0.279 \\
\hline $\begin{array}{l}\text { Intellectual- } \\
\text { cultural } \\
\text { orientation }\end{array}$ & 0.009 & 0.033 & 0.019 & 0.055 & 0.184 & 0.031 \\
\hline $\begin{array}{l}\text { Orientation to } \\
\text { outdoor } \\
\text { activities }\end{array}$ & 0.303 & 0.609 & 0.008 & 0.079 & 0.102 & 0.006 \\
\hline Moral aspects & 0.032 & $-0,076$ & 0.007 & 0.129 & 0.148 & 0.166 \\
\hline Organization & -0.032 & -0.045 & -0.077 & 0.490 & 0.026 & 0.199 \\
\hline Control & 0.349 & 0.145 & 0.190 & 0.181 & -0.237 & -0.123 \\
\hline
\end{tabular}

Table 1 shows that the indicator "commitment" has a significant direct relationship with "sovereignty of the territory" and an inverse relationship with the manifestation of "sovereignty of values". In other words, the extent of the positive attitude of family members to each other is associated with a sense of security in establishing boundaries between personal and nonpersonal territory in family interaction. However, focused attention (in the form of pressure, etc.) on family unity can negatively affect the possibility to manifest openly the individual life stance of each family member. The study also showed that the subject's self-identification through the perception of his/her physical body (the indicator "sovereignty of the physical body") is associated with the implementation of control and risks of conflict relations in the family (indicators "control", "conflict"). The result obtained is probably due to the fact that the frustration of the need for close people's love and understanding can cause intrapersonal conflict, as a result of which the subject begins to show rejection of his/her physicality and appearance, etc. Further, indicators of the family environment such as "organization" and "control" have a correlation with the parameter "sovereignty of habits", since distributing collective tasks among family members and monitoring them done are correlated with maintaining and observing the usual routine. In other words, the occurrence of time constraints on habitual actions that a family member considers "his/hers" contributes to the frustration associated with the inability to perform them. As the usual cycle of beginning and ending any action is significant for the subject, with all elements performed from beginning to end. For example, people may experience extreme discomfort and irritation when the usual duration of breakfast and morning routine, morning jog, the possibility of rest after work is violated. Also, we see that there is a correlation between the indicator "control" and "sovereignty of things" since things are a means of self-presentation, for example, a family member's personal cup standing on the table during his/her absence can perform the function of controlling and managing the environment, symbolizing the place and space of its "owner", etc.

To study the influence of noise factors (airborne, impact, and anthropogenic) on family members' psychological state during self-isolation, surveying was performed using the following methods: "Toronto Alexithymia Scale" (TAS), "Depression Scale" by A. Beck, "Interpersonal Dependency Inventory" by R. Hirschfeld, "Questionnaire for Assessing Subjective Responses to Various Types of Noise", taking into account the situation of long-term living in a confined space. There were three types of noise considered: airborne noise (the sound intensity level of the human voice, sounds of animals and weather phenomena, music streaming, etc.); impact noise (sounds associated with mechanical actions (different types of knocking, footsteps, etc.); anthropogenic noise (sounds of transport, working equipment and devices, the noise of industrial enterprises, etc.)

For the calculations to be convenient, the subjects were grouped into eight categories, respectively, taking into account the features of cohabitation: "childless families", "childless families living with progenitors", "families with one child", "families with one child living with progenitors", "families with two or more children", "families with two or more children living with progenitors", "partners who are not married", "partners who are not married living with progenitors".

To test the hypotheses, we analyzed the questionnaire results using the method of variance analysis. Table 2 below shows indicators of the statistical reliability of changes in resulting character in some indicators (variables) under the influence of existing conditions (factors). 
Table 2 Results of the analysis of acoustic noise influence on family members' states and feelings (taking into account the composition and characteristics of residence)

\begin{tabular}{|c|c|c|c|c|c|}
\hline Questioned & Factor & Variable & $\mathbf{N}$ & $\mathrm{F}_{\text {cr }}$ at $\mathrm{p} \leq \mathbf{0 . 0 5}$ & $\mathbf{F}_{\text {emp }}$ \\
\hline $\begin{array}{l}\text { Families with two or more } \\
\text { children }\end{array}$ & Anthropogenic noise & Low, medium level of alexithymia & 60 & 3.15 & 3.76 \\
\hline $\begin{array}{l}\text { Families with one child } \\
\text { living with progenitors }\end{array}$ & $\begin{array}{l}\text { Lack of self- } \\
\text { confidence }\end{array}$ & Impact noise & 51 & 3.19 & 7.18 \\
\hline $\begin{array}{l}\text { Childless families living } \\
\text { with progenitors }\end{array}$ & Airborne noise & Emotional support in others & 30 & 2.87 & 3.43 \\
\hline Single subjects & $\begin{array}{l}\text { Airborne noise, } \\
\text { anthropogenic noise }\end{array}$ & $\begin{array}{l}\text { Moderate depression (affective- } \\
\text { cognitive manifestations) }\end{array}$ & 28 & 3.01 & 4.6 \\
\hline $\begin{array}{l}\text { Single subjects living with } \\
\text { their progenitors }\end{array}$ & Airborne noise & Medium level of alexithymia & 28 & 3.01 & 6.63 \\
\hline Childless families & $\begin{array}{l}\text { Moderate depression } \\
\text { (affective-cognitive } \\
\text { manifestations) }\end{array}$ & $\begin{array}{l}\text { Impact noise } \\
\text { Airborne noise }\end{array}$ & 10 & 2.64 & 3.45 \\
\hline $\begin{array}{l}\text { Families with two or more } \\
\text { children living with } \\
\text { progenitors }\end{array}$ & Anthropogenic noise & Medium level of alexithymia & 20 & 2.72 & 8.37 \\
\hline Families with one child & Dependency & Impact noise & 10 & 2.64 & 4.22 \\
\hline
\end{tabular}

Table 2 shows that acoustic noise can be a factor causing the subject's particular mental state, and on the other hand, a specific personality trait can cause the subject to pay close attention to the surrounding sound environment associated with a specific life situation. The results showed that childless families and families living with progenitors are often affected by airborne noise in the form of various sounds associated with communicative pressure, flatness, etc., activating destructive and depressive experiences. During the survey, many subjects verbalized their assessments by adding emotional subject descriptions of sounds such as: "constantly dissatisfied grandmother's shouting", "a neighbour mumbling all night", "constantly sleepless ones at the other side of the wall", etc. The research found that taking various impact noise as a kind of aggressive intrusion may be due to personality characteristics associated with self-doubt and addiction. It was noted that the sound of various knocks (blows on surfaces, etc.) irritates and has a negative impact on family members who have no children and have moderate depression (affective-cognitive manifestations). These research participants described impact noise only within the framework of the topic of the violation of social interaction rules and norms during self-isolation not paying attention to the actual acoustic characteristics of the sound of this type of noise. For example, if the subjects who had no symptoms of depression characterized impact noise as "dull constant knocking", "a sonorous tramp of children's feet", etc., then the depressed participants with a low tolerance for uncertainty and dependency on social standards noted, when asked about airborne noise, as follows: "neighbours who have lost their shame and conscience and are making repairs in the quarantine", etc. Further, the results showed that the factor of anthropogenic noise is associated with the manifestation of alexithymia. In other words, this mechanical noise which has no connection with human nature can symbolize for the subject the lack of security in an environment that requires self-control and emotional suppression with the resulting inability to realize them.

\section{CONCLUSION}

In conclusion, we note that the situation with the COVID19 pandemic dictates the rules, according to which it is necessary to adapt to unexpected new conditions and constantly changing circumstances, such as the inability to live by usual routine with no experience in getting out of these conditions. The situation requires psychological mobilization and inclusion of the subject's internal resources, the depletion of which leads to a sense of helplessness and disorganization of the individual. The current situation contributed to liminal states in people, they were associated with the transition from one status of life to another, respectively, there are boundaries "before the quarantine" and "during the quarantine", where we are talking about mental states associated with the concepts of: "overcoming" and "not overcoming".

The research showed that the problems of the sovereignty of family members' personal psychological space in a situation of reduced social activity during the quarantine were manifested through organizational and managerial issues. In families with initially dysfunctional relationships, even before the coronavirus spread, mutual control and conflicts increased. The current psychological situation excluded the possibility of personalizing one's place (in a room, apartment, etc.), manifesting itself in the most vulnerable family members through the feeling of loneliness and lack of confirmation in the environment. There were acute issues with adaptation in long-term living in a confined space, to the effects of various acoustic noise (airborne, impact and anthropogenic), resulting in family members' showing irritation with the following development of various destructive mental states. 
The research has shown that today, the most popular are methods and means of providing psychological assistance, thanks to which the emerging situation of uncertainty will help to get rid of life patterns limiting and not relevant to the subject at present. Feelings of anticipation of novelty or the beginning of something ("blank sheet") will be an indicator of the individual's internal emotional and cognitive resources activated.

\section{REFERENCES}

[1] H. Selye, Stress Without Distress. Penguin Group (USA) Incorporated, 1975.

[2] B.A. Ammerman, T.A. Burke, R. Jacobucci, K. McClure, Preliminary Investigation of the Association Between COVID-19 and Suicidal Thoughts and Behaviors in the U.S., 2020, 6 April. DOI: https://doi.org/10.31234/osf.io/68djp

[3] D. Banerjee, T.S. Sathyanaray Rao, R. A. Kallivayali, A. Javed, Revisiting 'The Plague' by Camus: Shaping the 'social absurdity' of the COVID19 Pandemic, Asian Journal Psychiatry, Vol.

54, December 2020. DOI:

https://doi.org/10.1016/j.ajp.2020.102291

[4] O.M. Boyko, T.I. Medvedeva, S.N. Enikolopov, O. Yu. Vorontsova, O. Yu. Kazmina, The psychological state of people during the COVID-19 pandemic and the targets of psychological work, Psychological Research, 2020, V. 13, No. 70, P. 1.

[5] C. Brandbury-Jones RN, L. Isham, The pandemic paradox: The consequences of COVID-19 on domestic violence. Journal Clinical Nursing, Vol. 29, Issue13-14, July 2020, pp. 2047-2049. DOI:

https://doi.org/10.1111/jocn.15296

[6] D. N. Moreira, M. Pinto da Costa, The impact of the Covid-19 pandemic in the precipitation of intimate partner violence. International Journal of Law and Psychiatry, Volume 71, July-August 2020, DOI: https://doi.org/10.1016/j.ijlp.2020.101606

[7] V.N. Kunitsyna, N.V. Kazarinova, V.N. Pogolsha, Interpersonal Communication, Textbook for universities, Peter, 2001, P. 544.

[8] K. Lorentz, Aggression or the so-called evil, Publishing house AST, 2017, P. 352.

[9] S.K. Nartova-Bochaver, New version of the questionnaire "Sovereignty of psychological space 2010", Psychological journal, 2014, V. 35, No. 3, pp. 105-119.
[10] O. Bulgakova, Voice as a cultural phenomenon, New Literary Review, 2015, P. 568.

[11] E.N. Osin, The category of alienation in the psychology of education: history and prospects, Cultural-Historical Psychology, 2015, Volume 11, No. 4, pp. 79-88.

[12] T.N. Berezina, Multidimensional psyche. The inner world of personality, PER SE, 2012, P. 319.

[13] S.T. Gubina, Diagnostics and personality correction using musical means of influence, monograph, BIBLIO-GLOBUS, 2018, P. 316. 